\title{
Quantitative MR-neurographic parameters can determine and specify nerve injury in amyloid related polyneuropathy
}

\author{
Jennifer Kollmer ${ }^{1 *}$, Ernst Hund ${ }^{2}$, Stefan Schönland ${ }^{3}$, Ute Hegenbart ${ }^{3}$, Christoph Kimmich ${ }^{3}$, Arnt Kristen ${ }^{4}$, \\ Martin Bendszus ${ }^{1}$, Mirko Pham ${ }^{1}$
}

From First European Congress on Hereditary ATTR amyloidosis

Paris, France. 2-3 November 2015

\section{Background}

Hereditary transthyretin-familial-amyloid-polyneuropathy (TTR-FAP) usually manifests with a rapidly progressive, distally-symmetric polyneuropathy [Plante-Bordeneuve, $\mathrm{V}$. and G. Said, Lancet Neurol, 2011; Hund et al, Neurology 2001]. Recently, we were able to show that nerve-injury in TTR-FAP is detectable in-vivo by applying high-resolution MR-Neurography [Kollmer et al, Brain 2015]. The aim of the current study is to further quantify nerve-lesions at thigh-level where nerve-injury has been shown to be strongest, and to determine the ability of two quantitative parameters to clearly differentiate between symptomatic TTR-FAP, asymptomatic gene-carriers and healthy volunteers.

\section{Methods}

20 patients with confirmed mutations in the TTR-gene (13 with symptomatic TTR-FAP, 7 asymptomatic genecarriers), and 40 age/gender-matched healthy volunteers were prospectively included and classified according to neurological and electrophysiological findings. MR-Neurography with high structural resolution was performed on a 3T-MR-scanner (Magnetom/TIM-TRIO/Siemens):1) T2TSE-fs (TR/TE $5970 / 55 \mathrm{~ms}$, voxel-size $0.4 \times 0.3 \times 3.5 \mathrm{~mm}^{3}$ ); 2) Dual-echo-TSE-fs (TR 5210ms, TE1/TE2 12/73ms, voxelsize $0.4 \times 0.3 \times 3.5 \mathrm{~mm}^{3}$ ).

Manual voxel-vise segmentation of the sciatic/tibial/ common-peroneal nerve with subsequent fully-automatic classification as nerve-lesion-voxels was performed on each axial imaging slice (280/subject). The apparent-T2relaxation-time (T2app) and proton-spin-density as

'University of Heidelberg, Department of Neuroradiology, 69120, Heidelberg, Germany

Full list of author information is available at the end of the article distinct and quantifiable parameters that measure microstructural nerve-tissue-composition in-vivo [Heiland et al, Neurosci Lett. 2002] were then calculated for all nervelesion-voxels.

\section{Results}

One-way-ANOVA and post-hoc comparisons showed that proton-spin-density was highest in symptomatic TTR-FAP (549.97 \pm 35.78$)$, decreased significantly in asymptomatic gene-carriers $(406.09 \pm 28.22 ; \mathrm{p}=0.002)$, and further decreased significantly in controls $(286.56 \pm 10.04 ; \mathrm{p}<0.0001$ vs. symptomatic TTR-FAP and vs. asymptomatic gene-carriers $(\mathrm{p}=0.004)$.

Post-hoc comparisons showed that T2app was significantly increased only in symptomatic TTR-FAP $(103.92 \mathrm{~ms} \pm 6.4)$ vs. asymptomatic gene-carriers $(79.14 \mathrm{~ms}$ $\pm 1.8 ; \mathrm{p}=0.012)$ and vs. controls $(84.08 \mathrm{~ms} \pm 2.54 ; \mathrm{p}=0.003)$, but not between asymptomatic gene-carriers and controls $(\mathrm{p}=0.783)$.

\section{Conclusion}

For the first time, we were able to prove that alterations of the evaluated quantitative markers were highly specific: Asymptomatic carrier-status and symptomatic disease were both closely associated with a strong increase of proton-spin-density, while a significant increase of the T2-relaxation-time was found only in symptomatic TTR-FAP, but not in asymptomatic carriers. These findings suggest that proton-spin-density is more sensitive for the detection of early or even subclinical nerve-lesions, while T2app may serve to specifically differentiate increasing disease severity in already symptomatic TTR-FAP. 


\section{Authors' details}

'University of Heidelberg, Department of Neuroradiology, 69120, Heidelberg, Germany. ${ }^{2}$ University of Heidelberg, Department of Neurology, 69120, Heidelberg, Germany. ${ }^{3}$ University of Heidelberg, Medical Department $V$ (Amyloidosis Center), 69120, Heidelberg, Germany. ${ }^{4}$ University of Heidelberg, Medical Department III (Amyloidosis Center), 69120, Heidelberg, Germany.

Published: 2 November 2015

doi:10.1186/1750-1172-10-S1-014

Cite this article as: Kollmer et al:: Quantitative MR-neurographic parameters can determine and specify nerve injury in amyloid related polyneuropathy. Orphanet Journal of Rare Diseases 2015 10(Suppl 1):014.

Submit your next manuscript to BioMed Central and take full advantage of:

- Convenient online submission

- Thorough peer review

- No space constraints or color figure charges

- Immediate publication on acceptance

- Inclusion in PubMed, CAS, Scopus and Google Scholar

- Research which is freely available for redistribution

Submit your manuscript at www.biomedcentral.com/submit
C Biomed Central 